\title{
Behavioral basis of depth regulation in hatching and post-larval stages of the mud crab Eurypanopeus depressus*
}

\author{
S. D. Sulkin, W. F. Van Heukelem and P. Kelly \\ Horn Point Environmental Laboratories, Center for Environmental and Estuarine Studies, University of Maryland, Cambridge, \\ Maryland 21613, USA
}

\begin{abstract}
Stage I larvae of the benthic mud crab Eurypanopeus depressus Hay and Shore are negatively geotactic and show high barokinesis at a low response threshold, traits which should promote upward migration. A vertical temperature gradient of $10^{\circ} \mathrm{C}$ has no inhibitory effect on upward migration of first stage zoeae under laboratory conditions. Vertical stratification in estuarine spawning grounds should not influence movement to the surface of the hatching stage of estuarine brachyurans. Megalopae show a low response threshold to pressure increase, similar to earlier reports for megalopae of swimming crabs, indicating such sensitivity to pressure is probably widespread among brachyuran species. High degree of pressure sensitivity in brachyuran megalopae creates high precision in depth regulation, a trait important in successful recruitment to appropriate adult habitats.
\end{abstract}

\section{INTRODUCTION}

The euryhaline crab Eurypanopeus depressus Hay and Shore is a common brachyuran species occupying estuaries of the east coast of North America. The species typically inhabits oyster shoals which may be subtidal (Ryan, 1956) or intertidal (McDonald, 1982). Larval development consists of 4 zoeal stages and 1 megalopa (Ryan, 1956).

Vertical distribution of planktonic larvae of benthic crabs, such as Eurypanopeus depressus, will determine direction and rate of their dispersal in the estuarine and coastal marine environment. The hatching stage of many brachyuran species share common behavioral traits which promote movement to the surface and maintenance of position high in the water column (Sulkin, 1973, 1975; Forward and Costlow, 1974; Bentley and Sulkin, 1977; Latz and Forward, 1977; Sulkin et al., 1980). This ubiquitous phenomenon permits prediction of initial dispersal from the hatching site, subject to hydrographic features which characterize the spawning grounds. Such predictions can contribute to dispersal and recruitment models based on relatively conservative factors (Sulkin et al., 1980).

However, there are environmental stimuli present in

- Contribution No. 1382 of the Center for Environmental and Estuarine Studies the spawning area of estuarine crabs which could alter the basic pattern of vertical movement. Estuarine systems of the east coast of North America, which are characterized by substantial input of freshwater, typically are partially stratified and exhibit significant vertical gradients in salinity and temperature (Pritchard, 1952). Larvae which have hatched on the bottom and are migrating upwards in response to taxis and kinesis stimuli will encounter sharp salinity and temperature gradients through which they must pass if they are to reach the surface. Sulkin and Van Heukelem (1982) have shown that larvae of Callinectes sapidus Rathbun can pass through substantial gradients in salinity, but published reports on the ability of brachyuran larvae to penetrate sharp thermoclines are limited to one deep sea species (Kelly et al., 1982).

While the hatching stages of many brachyuran species share common behavioral traits which promote movement to surface waters, behavior of subsequent larval stages varies considerably among species. Of particular interest is the change which occurs during ontogeny in locomotory response to hydrostatic pressure, a trait which is largely responsible for precision in depth regulation. Change in response to pressure does occur, often resulting in lower sensitivity and less precise control for depth regulation in later zoeal stages (Sulkin, 1973; Bentley and Sulkin, 1977; 
Wheeler and Epifanio, 1978; Sulkin et al., 1980). On the other hand, megalopae of the swimming crabs Macropipus sp. and Callinectes sapidus show high sensitivity to pressure, in the case of C. sapidus reversing an ontogenetic trend (Naylor and Isaac, 1973; Sulkin and Van Heukelem, 1982). However, because pressure sensitivity is so closely related to depth regulation in the water column and because the transitional megalopa stage is characterized by both larval and adult traits, it is tempting to attribute the low response threshold to pressure in megalopae of these two species to the swimming habit of the adult.

We report here results of experiments designed to clarify the influence of a sharp thermal gradient on upward migration of the hatching stage and to determine whether low response threshold to pressure is present in the megalopa of a benthic brachyuran. The experiments were conducted on larvae of Eurypanopeus depressus, for which no studies of larval behavior have been reported. To determine whether general behavioral traits of the hatching stage of $E$. depressus are typical of other shallow-water brachyurans, results of experiments on sign of geotaxis and locomotory response to pressure also are presented. The results are discussed in the context of previously reported dispersal characteristics of brachyuran larvae.

\section{MATERIALS AND METHODS}

\section{Maintenance of ovigerous crabs and larvae}

Ovigerous Eurypanopeus depressus were collected from rock and oyster shell aggregations at Little Tom's Cove, Chincoteague National Wildlife Refuge, Assateague Island, Maryland, USA. Crabs were placed in $20 \mathrm{~cm}$ diameter glass bowls, containing 30pptS filtered seawater until hatching occurred.

Upon hatching, larvae were placed in glass bowls containing $100 \mathrm{ml}$ of filtered seawater (30pptS), with approximately 100 larvae per bowl. Cultures were kept in an incubator at either $15^{\circ}$ or $25^{\circ} \mathrm{C}$ with a light/dark cycle set at $14 / 10 \mathrm{~h}$. Cultures were transferred daily to clean seawater and were fed freshly-hatched nauplii of the brine shrimp Artemia sp.

Megalopae obtained from groups of zoeae raised at $25^{\circ} \mathrm{C}$ were held in larger volumes of seawater and were maintained as the zoeae had been. Experiments were conducted with megalopae within several days after molting

\section{Sign of geotaxis in Stage I}

The sign of geotaxis was tested following the general protocol of Sulkin et al. (1980). The method involves comparing changes in distributions over time between samples of sibling larvae placed into 2 identical observation chambers, one whose long axis is oriented horizontally (control) and one whose long axis is oriented vertically (experimental). The 2 chambers were constructed of $3 \mathrm{~mm}$ thick transparent 'lucite' and measured $30 \mathrm{~cm}$ in length and $5 \mathrm{~cm} \times 5 \mathrm{~cm}$ in cross section. Each chamber was marked off into 4 sections of equal length.

At the initiation of an experiment, samples of sibling larvae were placed at the bottom of the vertically oriented chamber and at one end of the horizontally oriented chamber. Distribution of larvae among the 4 sections of each chamber were noted at 10-min intervals for $30 \mathrm{~min}$. Movement of larvae along the axis of the horizontal chamber in total darkness results from random (non-oriented) swimming activity. Both oriented and random movement can occur along the axis of the vertical chamber in the absence of light. If the shift in distribution in the vertical chamber exceeds that measured in the horizontal chamber, the result is attributed to negative geotaxis; if the shift in the vertical chamber is less than that measured in the horizonal chamber, the result is attributed to positive geotaxis (Sulkin et al., 1980).

Larvae of Eurypanopeus depressus from 10 different broods were tested for sign of geotaxis in this fashion. All tests were conducted at $25^{\circ} \mathrm{C}$ with larvae cultured at that temperature. The non-parametric Mann-Whitney-Wilcoxon test was used to determine differences in larval distribution between vertically and horizontally oriented chambers at the end of $30 \mathrm{~min}$ (Steele and Torrie, 1960).

\section{Response to hydrostatic pressure in Stage I}

The effect of pressure increment on swimming rate was measured directly. A sample of larvae $(n=30)$ was placed into an observation chamber constructed of $6 \mathrm{~mm}$ thick tubular 'lucite', measuring $15 \mathrm{~cm}$ in length and $5 \mathrm{~cm}$ in diameter. A diffuse white light $\left(75 \mathrm{~W} \mathrm{~m}^{-2}\right)$ was positioned at each end of the horizontally oriented chamber. The chamber was attached to a pressure generator, consisting of a piston screw pump which develops pressure in a small volume by fluid compression. Pressure in the observation chamber was controlled manually by turning a turnstile on the generator and reading the resulting pressure from a gauge positioned between the pump and the chamber (Kelly et al., 1982)

The sample of larvae was induced to swim along the long axis of the observation chamber by shining the lights alternately from each end. Individuals were timed as they swam across a premeasured track in the 
middle of the chamber. After approximately 20 individuals had been timed, the pressure was raised by $0.2 \mathrm{~atm}$ and a second set of swimming speeds was recorded. This procedure was repeated for pressure increments of $0.2 \mathrm{~atm}$ up to 1.0 atm above ambient and for a total increment of $1.5 \mathrm{~atm}$ above ambient $(0.0,0.2$, $0.4,0.6,0.8,1.0,1.5 \mathrm{~atm})$. The entire experiment was repeated with groups of sibling larvae from 5 different broods at $15^{\circ} \mathrm{C}$ and from 6 broods at $25^{\circ} \mathrm{C}$.

The effect of pressure and temperature on rate of swimming was tested by two-way Analysis of Variance after the F-max test validated the use of parametric statistics $(\mathrm{F}-\mathrm{max}=1.38 ; P>0.05)$.

\section{Response of Stage I larvae to a thermocline}

The effect of a sharp thermocline on upward migration of Stage I larvae was tested by inducing a sample of larvae to swim upward through a temperature gradient. Their ability to do so was compared to a control in which sibling larvae similarly were induced to swim upwards in an identical tank in which there was no temperature gradient (Kelly et al., 1982).

A vertically-oriented 'lucite' observation chamber $45 \mathrm{~cm}$ long and $5 \mathrm{~cm} \times 5 \mathrm{~cm}$ in cross section, was surrounded on 3 sides by a water bath. The water bath was divided into separate upper and lower halves. Cold water $\left(15^{\circ} \mathrm{C}\right)$ was pumped through coils in the lower water bath from the bottom, and warm water $\left(25^{\circ} \mathrm{C}\right)$ was pumped through a separate set of coils in the upper water bath from the top. The water within each bath was mixed by use of airstones. The result was a sharp temperature gradient in the observation chamber such as that shown in Fig. 3. Temperature was measured before and after each experiment by a YSI Model 47 telethermometer with 12 thermistors permanently mounted along the length of the observation chamber. The control system was identical to the experimental one except that the temperature was a constant $15^{\circ} \mathrm{C}$ throughout the length of the observation chamber.

Each observation chamber was marked off into three sections of equal length, the middle one containing the thermocline in the experimental system. Samples of sibling larvae were introduced to the bottom of each chamber by long 'lucite' pipettes, taking care not to disrupt the thermocline. When the thermocline was again stable, a diffuse white light $\left(75 \mathrm{~W} \mathrm{~m}^{-2}\right)$, fixed at the top of each chamber, was used to induce upward movement of the larvae. The number of larvae in each of the 3 sections of each chamber was recorded at 10 min intervals for $30 \mathrm{~min}$. A comparison of the percent of the total sample in the top sections of the control and thermocline chambers after $30 \mathrm{~min}$ was used to indi- cate whether vertical movement in the experimental chamber had been affected by the thermocline.

Eight groups of larvae from 6 different broods were tested in this fashion. Larvae had been maintained in culture at $15^{\circ} \mathrm{C}$ since hatching and were dark-adapted for $2 \mathrm{~h}$ prior to testing. The data were subjected to arc sine transformation, the F-max test for homogeneity of variance $(F-\max =2.15 ; P>0.05)$, and the paired t-test to determine whether differences between experimental and control tanks were significant.

\section{Responses to hydrostatic pressure in the megalopa}

Because megalopae characteristically alternate swimming and crawling activity, it is difficult to measure swimming rates directly as was done for zoeal Stage I. The method used here for megalopae was the same as that reported by Sulkin and Van Heukelem (1982) for determining barokinesis in Callinectes sapidus megalopae and is based on the same principle as that employed by Naylor and Isaac (1973). The method utilizes the combined effects of kinesis and taxis and exploits the fact that when locomotory activity increases, megalopae will move upwards due to photo- and/or geotactic orientation responses.

The experiments employed two identical observation chambers, each measuring $45 \mathrm{~cm}$ long and $5 \mathrm{~cm} x$ $5 \mathrm{~cm}$ in cross section. Each chamber was marked off into 7 segments of equal length and 1 chamber (experimental) was connected to a mercury manometer. Pressure could be increased in the sealed experimental chamber by raising the distal end of the manometer.

The following general experimental protocol was followed. A sample $(n=10)$ of sibling megalopae was placed at the bottom of each vertically-oriented chamber. Pressure in the experimental chamber was raised by 2.5 pounds per square inch (psi). One minute later, the distributions of megalopae among the 7 segments of the 2 tanks was measured. The pressure then was raised to 5 psi above ambient, followed 1 min later by measurement of megalopa distribution. This sequence was repeated for $8 \mathrm{~min}$ until a total increment of 20 psi had been obtained. The experiment was repeated 10 times with megalopae from 8 broods. Percent of each sample above the bottom segment was calculated and the mean percents plotted against time (pressure increment). For each time interval, the percent above the bottom segment was compared between experimental and control chambers. The Fmax test in each case was not significant $(P>0.05)$ and the arc sine transformed data were subjected to a series of paired t-tests.

In 6 of the 10 tests, pressure was reduced to ambient immediately after the $8 \mathrm{~min}$ (20 psi) reading and a 
measurement of resulting distribution made 1 min later. In 4 of the 10 tests, pressure was maintained at 20 psi through Minute 15 and a measurement of distribution was made at that time. Pressure then was reduced to ambient and a new determination of distribution made 1 min thereafter. A comparison of distributions after return to ambient pressure under these 2 conditions was made by a Stucient's t-test, with arc sine transformed data ( $F-\max =5.49 ; P>0.05)$.

In a separate test, megalopae were subjected to an immediate pressure increase of 20 psi. Distributions in control and experimental tanks were determined after $8 \mathrm{~min}$. The experiment was repeated 6 times with megalopae from 2 broods. Distribution of megalopae at 20 psi under the 3 different test conditions described above were compared using Analysis of Variance, with arc sine transformed data (F-max $\left.=2.07_{i} P>0.05\right)$.

\section{RESULTS}

\section{Geotaxis in Stage I}

Fig. 1 shows the results of experiments designed to determine sign of geotaxis in Stage I larvae. Shown are the mean proportional distributions of 10 independent tests at the beginning of the experiment (when all larvae were at one end of the horizontal tank or at the bottom of the vertical tank) and those attained after $30 \mathrm{~min}$. Movement along the axis of the vertical tank far exceeded that attributable to random activity (control tank). The Mann-Whitney-Wilcoxon test indicates a significant difference in distribution between the 2 tanks at the end of $30 \mathrm{~min}(P<0.01)$. The movement in the vertical tank is the result of oriented movement and indicates the presence of negative geotaxis.

$T I M E: O$

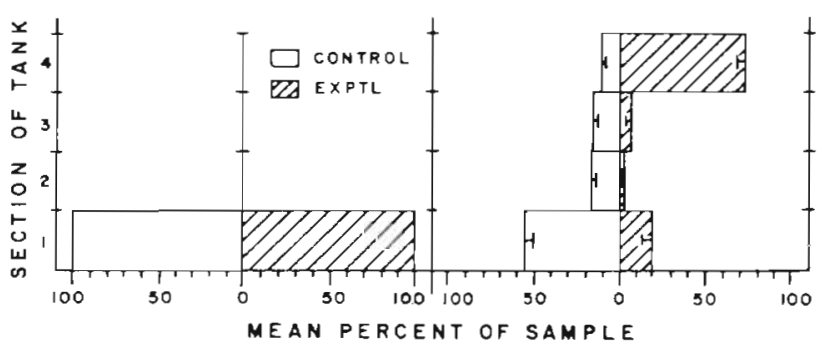

Fig. 1. Eurypanopeus depressus. Geotaxis in Stage I. Mean proportional distributions of samples of larvae among 4 sections of experimental and control chambers at the initiation and conclusion of the experiment. Horizontal T-bars indicate 1 standard error

\section{Kinesis responses in Stage I}

Shown in Fig. 2 are mean swimming rates for Stage I larvae in pressures up to $1.5 \mathrm{~atm}$ above ambient at $15^{\circ}$

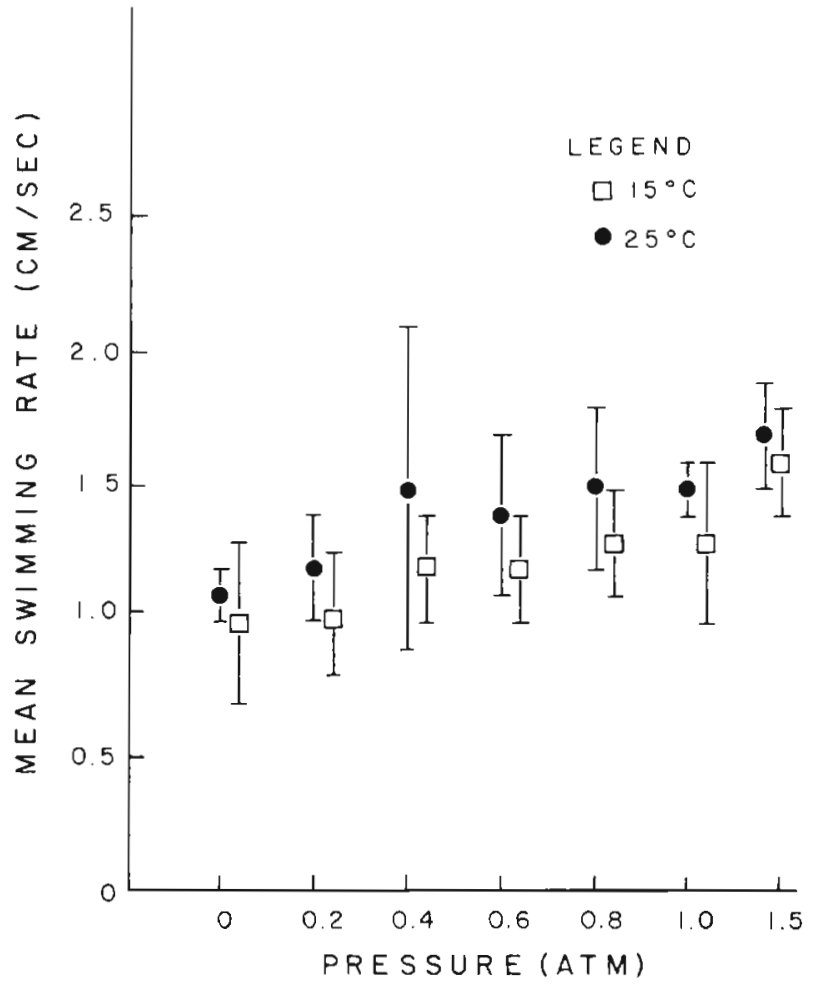

Fig. 2. Eurypanopeus depressus. Mean swimming ratio ( \pm 1 standard deviation) for Stage I larvae in pressure increments as indicated at 15 and $25^{\circ} \mathrm{C}$

and $25^{\circ} \mathrm{C}$. The two-way ANOVA indicates significant differences due both to pressure increment $(P<0.001)$ and to temperature $(P<0.01)$ with no significant interaction $(P>0.10)$. High barokinesis and high thermokinesis are indicated by these results.

\section{Response to a thermocline in Stage I}

Fig. 3 shows the mean proportional distributions of 8 groups of larvae induced to swim upwards through a thermocline and through a control tank in which no thermal gradient was present. Shown are mean values at the initiation of the experiment (time $=0$ ) and at its conclusion 30 min later. Larvae in the top third of the experimental tank have traversed the $10^{\circ} \mathrm{C}$ thermocline in the middle section (far right diagram in Fig. 3). A comparison of the percent of the sample in the top section between the experimental and control tanks reveals no significant difference (t-test for paired data with arc sine transformation: $0.640 ; P>0.50$ ).

Observation of the swimming behavior of individual larvae indicated a change in swimming behavior when larvae entered the thermal gradient. There was a temporary accumulation of larvae in the middle section of the tank which resulted from either reduced swimming rate or temporary cessation of swimming. As indicated 
TIME = O

Fig. 3. Eurypanopeus depressus. Mean proportional distributions of samples of Stage I larvae among 3 sections of experimental (thermocline) and control chambers at the initiation and conclusion of the experiment. Horizontal T-bars indicate 1 standard error. Shown at the far right is a representative temperature profile for the control (dashed line) and experimental (solid line) chambers

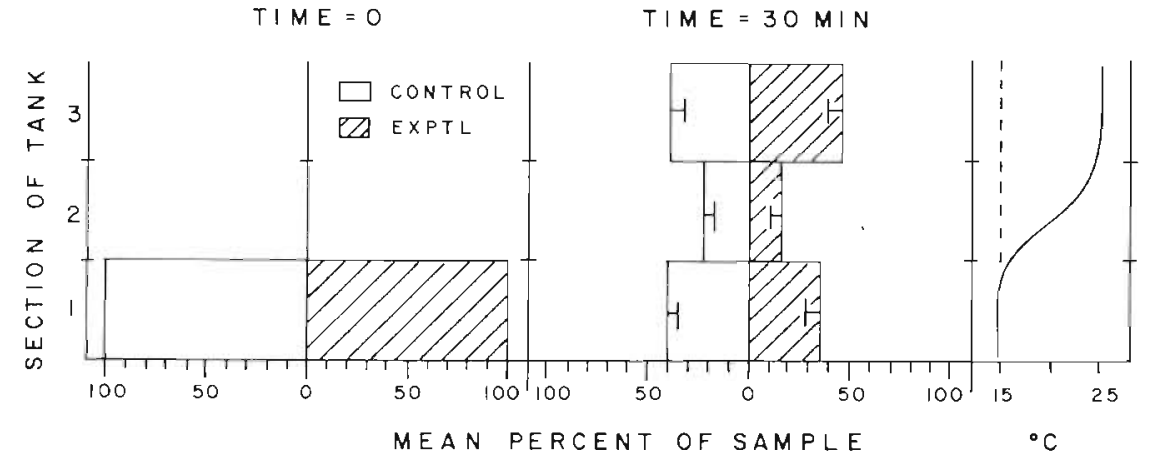

in Fig. 3, most of the larvae (as compared to the control) eventually penetrated the thermocline and resumed normal swimming activity. The thermocline tested has only a very temporary disruptive effect on upward migration in the hatching stage of Eurypanopeus depressus and does not cause significant inhibition of upward migration.

\section{Response of megalopae to pressure}

Change in distribution with stepwise increase in hydrostatic pressure (up to 20 psi) is shown in Fig. 4. Also shown are the distributions for megalopae maintained at 20 psi for an additional 7 min (until Minute 15) and that taken 8 min after megalopae had been subjected initially to a single increment of 20 psi above ambient. There is an obvious increase in the percent of the sample above the bottom as pressure is increased. When the mean percentages above bottom of experi- mental and control chambers were compared directly by paired t-tests at each time interval, significant differences were present in each case $(P<0.001)$. When the distributions measured at 20 psi under the 3 different test conditions were compared by Analysis of Variance, no significant difference was found ( $P$ $>0.05$ ). These results indicate the presence of high barokinesis with a threshold for a significant level of response as low as 2.5 psi increment.

Fig. 5 illustrates the results of reducing pressure to ambient after increasing it to $20 \mathrm{psi}$. Within $1 \mathrm{~min}$ of pressure drop, there was a significant shift in the samples back toward the bottom of the chamber, although not all megalopae had returned within $1 \mathrm{~min}$. The pattern was the same whether the pressure was dropped immediately after being increased to 20 psi ( $\mathrm{t}=$ $8 \mathrm{~min}$ ) or whether it was maintained at 20 psi for an additional $7 \mathrm{~min}$ (Student t-test, $P>0.05$ ). This implies rapid reversibility of response.
Fig. 4. Eurypanopeus depressus. Mean percent ( \pm 1 standard error) of sample above bottom of experimental observation chamber as a function of pressure increments applied as indicated. Also shown is corresponding distribution for control chambers maintained throughout at ambient pressure

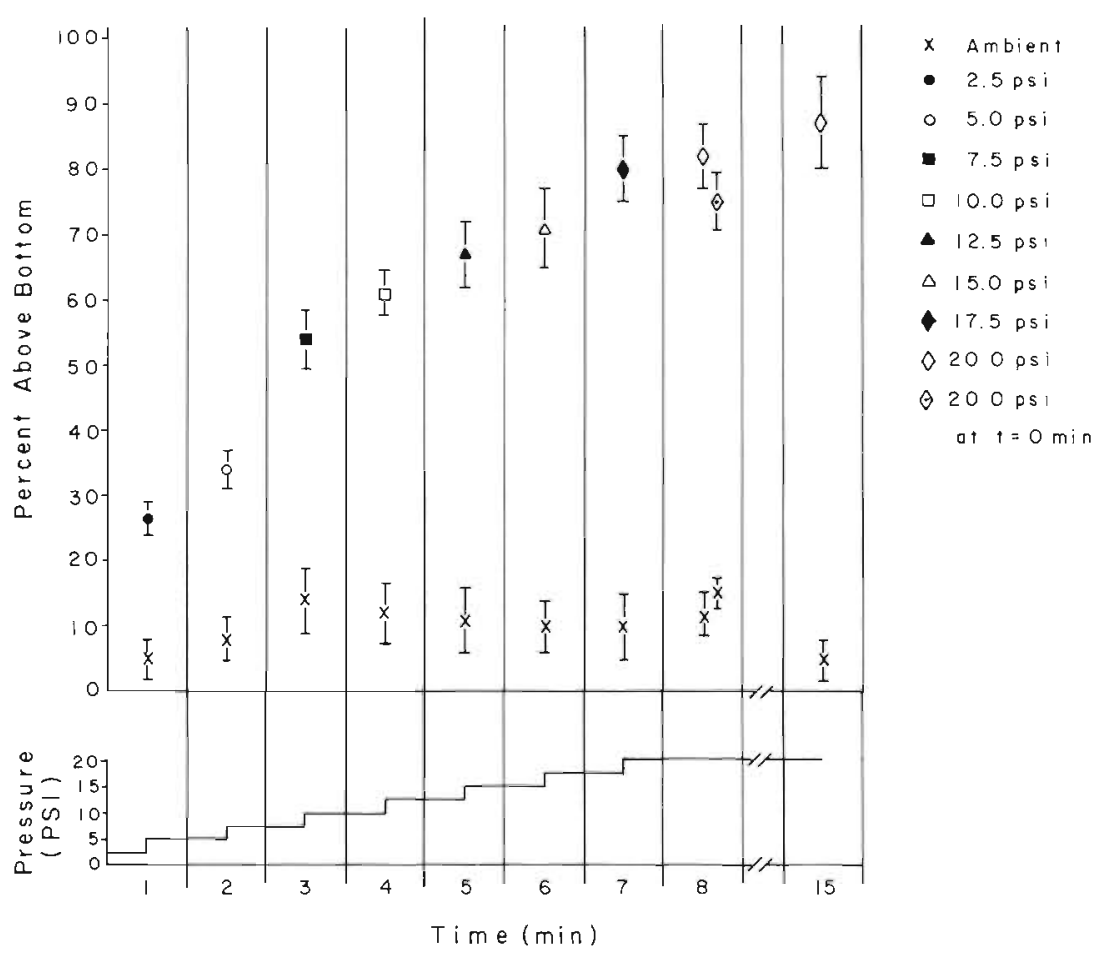




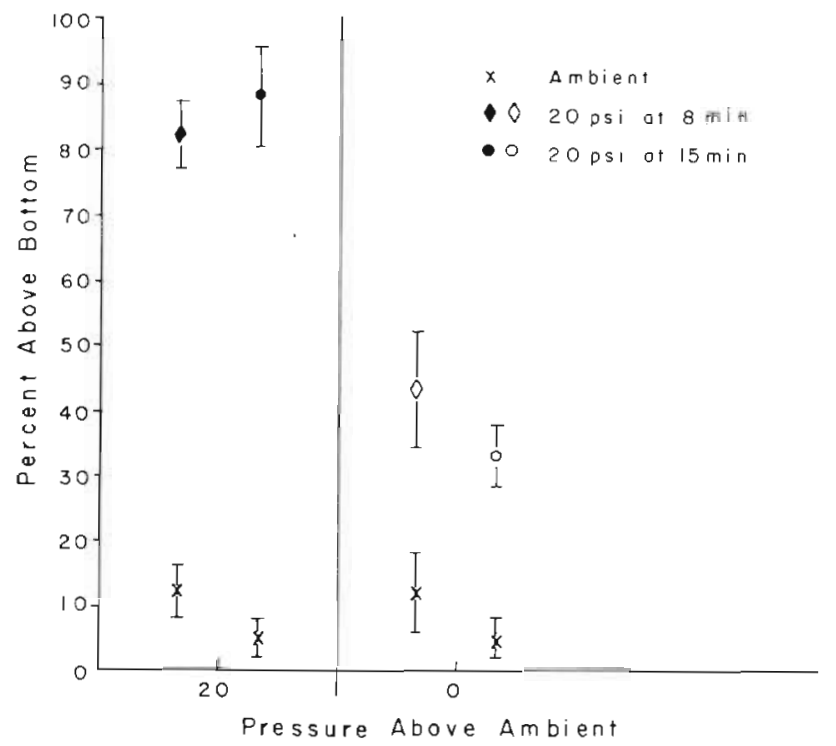

Fig. 5. Eurypanopeus depressus. Mean percent ( \pm 1 standard error) of sample above bottom of experimental chamber for megalopae exposed to stepwise increment of pressure up to 20 psi at $8 \mathrm{~min}$ (solid diamond), followed by reduction of pressure to ambient (open diamond) and megalopae maintained at 20 psi through Minute 15 (solid circle) before reduction to ambient pressure (open circle). Also shown is corresponding distribution of control chambers maintained throughout at ambient pressure

\section{DISCUSSION}

\section{Depth regulation at Stage I}

Results for Stage I of Eurypanopeus depressus indicate the behavioral basis for depth regulation typical of that described for other shallow water crab species (Sulkin, 1973; Wheeler and Epifanio, 1978; Sulkin et al., 1980). Stage I larvae show the same pervasive negative geotaxis reported for early zoeal stages of Panopeus herbstii and Leptodius floridanus (Sulkin, 1973), Rhithropanopeus harrisii (Ott and Forward, 1976), Cancer irroratus (Bigford, 1979), Callinectes sapidus (Sulkin et al., 1980), and Geryon quinquedens (Kelly et al., 1982). Negative geotaxis is complemented by high barokinesis at a low pressure threshold. As larvae sink passively into deeper waters, their swimming rate will increase, an active response which in combination with negative geotaxis will result in upward movement. Depth regulation thus occurs as a result of negative feedback between negative buoyancy on the one hand and orientation and kinesis responses on the other. The precision of depth regulation largely will depend upon the sensitivity of the larvae to change in pressure. The hatching stage of $E$. depressus shows the high sensitivity to pressure which seems characteristic of crab species which release their larvae in comparatively shallow estuarine and coastal marine waters (Sulkin, 1973; Bentley and Sulkin, 1977; Bigford, 1977; Wheeler and Epifanio, 1978).

Stage I larvae are able to swim upward through a very sharp thermocline with little apparent disruption, a somewhat surprising phenomenon in light of reported behavioral sensitivity to temperature change among larvae of other invertebrate taxa (Ewald, 1912; Fraenkel, 1931; Thorson, 1964). Furthermore, zooplankton have been shown to collect at vertical density gradients imposed by salinity discontinuities (Lance, 1962; Harder, 1968; Roberts, 1971). However, there is evidence that crab larvae may be comparatively insensitive to temperature change and to vertical discontinuities. Sulkin et al. (1980) reported that Stage I larvae of Callinectes sapidus maintained the same swimming rate at $15^{\circ}$ as at $25^{\circ} \mathrm{C}$. Ott and Forward (1976) showed that sign of phototaxis was not affected by temperature in Rhithropanopeus harrisii larvae, a result confirmed by Sulkin and Van Heukelem (1982) for larvae of $C$. sapidus. Sulkin and Van Heukelem (1982), furthermore, showed that only extremely large haloclines ( $\Delta S=10 \mathrm{ppt}$ ) inhibited upward migration of first stage $C$. sapidus larvae. However, movement upward through substantial thermoclines also has been shown for Stage I larvae of Geryon quinquedens (Kelloy et al., 1982), a benthic species which occupies depths of from 200 to $1,500 \mathrm{~m}$ as an adult.

The observed behavior of individual Eurypanopeus depressus larvae in the region of the thermal gradient suggests that normal swimming behavior is disrupted temporarily, but that penetration even of extraordinarily large thermal discontinuities readily occurs. Indeed, the tendency of larvae to swim faster as they begin to penetrate higher temperature (Fig. 2) may stimulate penetration of the thermocline.

Available evidence on behavior of crab larvae in response to both thermal and salinity discontinuities suggests that the presence of a pycnocline in nature will have little substantial effect on vertical migration that is stimulated by basic behavioral traits. Movement to surface waters, even in highly stratified estuaries, is the likely consequence of the behavioral traits characteristically shown by early stage brachyuran larvae.

\section{Pressure response in megalopa}

Our results indicate a straightforward response on the part of Eurypanopeus depressus megalopae to pressure increment. Because megalopae are negatively buoyant, a shift in distribution upward must be the result of active movement (mediated by orientation stimuli). An increase in pressure results in an increase in locomotory activity which is manifest by movement 
up from the bottom in a characteristic percentage of the sample (Fig. 4). The experimental design and protocol used here indicates a variable threshold of sensitivity among individuals which is characteristic of a given pressure increment and is unaffected by the time (within experimental limits) to which they have been exposed to subthreshold pressures.

The threshold level of response of Eurypanopeus depressus megalopae is similar to that reported here for Stage I zoeae and it is obvious that the megalopae are responsive to small pressure increments. The nature of the response can have consequences on dispersal.

The initial response threshold is low enough to suggest sensitivity of some megalopae to pressure variations of tidal amplitude. This could be significant because megalopae both swim and crawl on the bottom. Megalopae suspended in the water column will rise and fall with the tidal wave and thus will not be exposed to tidally-induced changes in pressure. However, megalopae positioned on the bottom can perceive the change in hydrostatic pressure associated with the tidal wave. Increase in pressure associated with flooding tides could induce a small percentage of a benthic population of megalopae to swim up and thereby selectively exploit tidal flow.

However, a typical depth regulation mechanism is likely for megalopae up in the water column. As megalopae sink and are thus exposed to increasing pressure, the general level of locomotory activity will increase as response thresholds are passed, resulting in upward movement mediated by the appropriate orientation stimuli. In Eurypanopeus depressus megalopae, the behavioral mechanism is present to promote upward movement and maintenance of position high in the water column.

\section{Ontogeny of pressure response in brachyurans}

Movement towards the surface soon after hatching is a phenomenon widespread among larvae of invertebrate taxa (e.g. Thorson, 1950; Mileikovsky, 1971; Longhurst, 1976). This ubiquitous phenomenon is stimulated by combinations of behavioral traits, including negative geotaxis and/or positive phototaxis and appropriate kinesis responses. In brachyuran crabs, high barokinesis, stimulated at a low response threshold, seems to be an integral part of the mechanism.

Vertical distribution of intermediate and late zoeal stages is less consistent within species than is the case for Stage I and varies widely among species according to field reports (Sandifer, 1973, 1975; Goy, 1976; Lough, 1976; Smyth, 1980; Ana Dittel, Charles
Epifanio, Anthony Provenzano, pers. comm.). Experimental evidence indicates a more varied response to pressure among these stages and among species than is the case with Stage I. In Leptodius floridanus (Sulkin, 1973; Wheeler and Epifanio, 1978) and Cancer irroratus (Bigford, 1977), there is reduction in sensitivity to pressure increase in late zoeal stages. Callinectes sapidus shows reversal from high barokinesis early in development to low barokinesis in late zoeal stages (Sulkin et al., 1980). Of species tested to date, only larvae of Rhithropanopeus harrisii (Bentley and Sulkin, 1977; Wheeler and Epifanio, 1978) show high barokinesis throughout zoeal development. Wheeler and Epifanio attributed the maintenance of pressure sensitivity through ontogeny in $R$. harrisii to its mesohaline estuarine habitat and its more rigorous requirement for high precision in depth regulation to assure retention within favorable regions of the estuary.

Results reported here clearly demonstrate that megalopae of a benthic brachyuran crab respond to small changes in hydrostatic pressure. These results suggest that the phenomenon is not limited to species whose adults are nektonic, but rather is a more generalized adaptation in the megalopa stage of brachyuran crabs. Reports on vertical distribution of megalopae indicate a propensity for swarming, particularly in surface waters (Williams, 1971; Lough, 1976; Epifanio, Provenzano, pers, comm.). Furthermore, the megalopa stage is one of transition between the zoeal stage which is invariably planktonic in brachyurans and the post-metamorphic stage whose habitats vary widely among species. Selection is likely for behavioral traits which promote successful recruitment to settlement sites appropriate to adult life. Phenomena such as swarming at discrete depths or circatidal activity rhythms may be the result of such selection. It is reasonable to speculate, therefore, that precision in depth regulation will be highly adaptive in the post-larva and that low response threshold to pressure, characteristic of widely divergent species, is the operative behavioral mechanism.

Acknowledgements. The authors wish to acknowledge the technical assistance of Ms. Sharon Van Aller, who was supported by the National Science Foundation through its Undergraduate Research Participation program. Part of the research reported here is from the thesis of the third author and is in partial fulfillment of the requirement of the Masters of Science degree in the Department of Zoology, University of Maryland, College Park. The research was supported by the Maryland Sea Grant Program (Project R/F-15). The senior author wishes to thank the Friday Harbor Laboratories, University of Washington, and the Woods Hole Oceanographic Institution for providing resources required to complete the manuscript. 


\section{LITERATURE CITED}

Bentley, E., Sulkin, S. D. (1977). The ontogeny of barokinesis during the zoeal development of the xanthid crab Rhithropanopeus harrisii (Gould). Mar. Behav, Physiol. 4: 275-282

Bigford, T E. (1977). Effects of oil on behavioral responses to light, pressure, and gravity in larvae of the rock crab Cancer irroratus. Mar Biol. 43: 137-148

Bigford, T. E. (1979). Ontogeny of light and gravity responses in the rock crab Cancer irroratus. Mar. Biol. 52: 69-76

Ewald, E. F. (1912). On artificial modification of light reaction and the influence of electrolytes on phototaxis. J. exp. Biol. 13: 591-612

Forward, R. B., Jr., Costlow, J. D., Jr. (1974). The ontogeny of phototaxis by larvae of the crab Rhithropanopeus harrisii. Mar. Biol. 26: 27-33

Frankel, G. (1931). Die Mechanik der Orientierung der Tiere in Raum. Biol. Rev. 6: 36-87

Goy, J. W. (1976). Seasonal distribution and the retention of some decapod crustacean larvae within the Chesapeake Bay, Virginia. M.S. thesis, Old Dominion University, Norfolk, Virginia

Harder, W. (1968). Reactions of plankton organisms to water stratification. Limnol. Oceanogr. 13: 156-160

Kelly, P., Sulkin, S. D., Van Heukelem, W. F. (1982). A dispersal model for larvae of the deep sea red crab Geryon quinquedens based upon behavioral regulation of vertical migration in the hatching stage. Mar. Biol. 72: 35-43

Lance, J. (1962). Effects of water of reduced salinity on the vertical migration of zooplankton. J. mar. biol. Ass. U.K. 42: $131-154$

Latz, M. U., Forward, R. B., Jr. (1977). The effect of salinity upon phototaxis and geotaxis in a larval crustacean. Biol. Bull. mar. biol. Lab., Woods Hole 153: 163-179

Longhurst, A. R. (1976). Vertical migration. In: Cushing, D. H., Walsh, J. J. (eds.) The ecology of the seas. Blackwell Scientific, Oxford, England, p. 116-137

Lough, R. G. (1976). Larval dynamics of the dungeness crab Cancer magister off the central Oregon coast, 1969-1971. Fish. Bull U.S. 74: 353-376

McDonald, J. (1982). Divergent life history patterns in the cooccurring intertidal crabs Panopeus herbstii and Eurypanopeus depressus (Crustacea: Brachyura: Xanthidae). Mar. Ecol. Prog. Ser. 8: 173-180

Mileikovsky, S. A. (1971). Types of larval development in marine bottom invertebrates, their distribution and ecological significance: a re-evaluation. Mar. Biol. 10: $193-213$

Naylor, E., Isaac, M. J. (1973). Behavioral significance of pressure responses in megalopa larvae of Callinectes sapidus and Macropipus sp. Mar. Behav. \& Physiol. 1: 341-350

Ott, F. S., Forward, R. B., Jr. (1976). The effect of temperature on phototaxis and geotaxis by larvae of the crab Rhithropanopeus harrisii (Gould). J. exp. mar. Biol. Ecol. 23 97-107

Pritchard, D. W. (1952). Salinity distribution and circulation in the Chesapeake Bay estuarine system. J. mar Res. 11: 106-123

Roberts, M. H., Jr. (1971). Larval development of Pagurus longicarpus Say reared in the laboratory. II. Behavioral responses to salinity discontinuities. Biol. Bull. mar. biol. Lab., Woods Hole 140: 489-501

Ryan, E. P. (1956). Observations on the life histories and the distribution of the Xanthidae (mud crabs) of Chesapeake Bay. Am. Midl. Nat. 56: 138-162

Sandifer, P. A. (1973). Distribution and abundance of decapod crustacean larvae in York River estuary and adjacent lower Chesapeake Bay, Virginia, 1968-69. Chesapeake Sci. 14: 235-257

Sandifer, P. A. (1975). The role of pelagic larvae in recruitment to populations of decapod crustaceans in the York River estuary and adjacent lower Chesapeake Bay, Virginia. Estuar. coast. mar. Sci. 3: 269-279

Smyth, P. O. (1980). Callinectes (Decapoda: Portunidae) larvae in the middle Atlantic bight, 1975-77. Fish. Bull. U.S. 78: 251-265

Steele, R. G. D., Torrie, J. H. (1960). Principles and procedures of statistics. McGraw-Hill, New York.

Sulkin, S. D. (1973). Depth regulation of crab larvae in the absence of light. J. exp. mar. Biol. Ecol. 13: 73-82

Sulkin, S. D. (1975). The influence of light in the depth regulation of crab larvae. Biol. Bull. mar. biol. Lab., Woods Hole 148: 33-343

Sulkin, S. D., Van Heukelem, W. (1982). Larval recruitment in the crab Callinectes sapidus Rathbun: an amendment to the concept of larval retention in estuaries. In: Kennedy, $V$ (ed.) Estuarine comparisons. Academic Press, New York, p. 459-475

Sulkin, S. D., Van Heukelem, W., Kelly, P., Van Heukelem, L. (1980). The behavioral basis of larval recruitment in the crab Callinectes sapidus Rathbun: a laboratory investigation of ontogenetic changes in geotaxis and barokinesis. Biol. Bull. mar. biol. Lab., Woods Hole 159: 402-417

Thorson, G. (1950). Reproduction and larval ecology of marine bottom invertebrates. Biol. Rev. 25: 1-45

Thorson, G. (1964). Light as an ecological factor in the dispersal and settlement of larvae of marine bottom invertebrates. Ophelia 1: 167-208

Wheeler, D. E., Epifanio, C. E. (1978). Behavioral response to hydrostatic pressure in larvae of two species of xanthid crabs. Mar Biol. 46: 167-174

Williams, A. B. (1971). A ten-year study of meroplankton in North Carolina estuaries: annual occurrence of some brachyuran developmental stages. Chesapeake Sci. 12 $53-61$ 